\title{
“NADA VIVE MÁS QUE EL FANTASMA"
}

\author{
"Nothing Lives but the Ghost" \\ Pablo Bernardo Sánchez Gómez \\ Universidad Nacional de Educación a Distancia \\ pabersg@gmail.com
}

Reseña de: Rocha, D. (2019). Deconstrucción de la pena de muerte. Madrid: Oficina de Arte y Ediciones. 136 p.

Uno podría pensar que la cuestión de la pena de muerte no es de especial relevancia en un contexto como el nuestro, Europa, donde esta pena ha sido abolida en todos los países que conforman la unión. No obstante, sin obviar el hecho de que la pena de muerte continúa existiendo en sesenta países, de lo que se trata verdaderamente en esta obra es de pensar "la imposibilidad de su no existencia". Y para tratar esta aporía, esta imposibilidad, esta necesidad, Delmiro Rocha parte del seminario impartido por Jacques Derrida en torno a la pena de muerte sin por ello limitarse, no obstante, a un simple comentario o exposición de lo allí tratado. Por el contrario, el autor se propone explorar seis cuestiones abiertas en este seminario a través de las que muestra que una deconstrucción de la pena de muerte no consiste simplemente en una reflexión política sino, mucho más que esto, en pensar el trasfondo teológicopolítico en el que la pena de muerte se asienta, pudiendo así llevar a cabo una interrogación profunda en torno a la soberanía, la sexualidad y la animalidad.

El primero de los capítulos comienza con una proposición que atraviesa la totalidad del texto: "la idea de la pena de muerte es indisociable del concepto de soberanía" (p. 15). En este sentido, durante estas primeras páginas, y a través de una lectura de textos canónicos en torno a la cuestión de la soberanía, como Bodin o Kantorowicz, Delmiro Rocha se ocupa de mostrar cómo la noción de "soberanía" se ha venido construyendo históricamente en cuanto acto o decisión que viene del Otro, pero de un otro tal que no tiene Otro, del paradójico "Otro mismo", del "Gran Otro". De este modo, siendo la ley o la norma, y con ella la ley que establece la pena de muerte, un emisión de este "Otrísimo", el soberano se sitúa más allá, "por encima" de la ley: como recuerda el Delmiro Rocha, el término "soberanía" no expresa sino "lo más alto", "lo máximamente alto", esto es, "el Altísimo". Ahora bien, si el soberano, el Altísimo, es el único que puede decidir sobre la vida y la muerte de sus súbditos, siendo por tanto el único que establece la ley para matar legalmente, ¿no sería también el soberano el único capaz de dar muerte a la pena de muerte? En última instancia, solo el Altísimo, solo Dios, en cuanto soberano, en cuanto legislador de la pena de muerte, tiene el poder de abolir esta misma pena. Se podría complementar, por tanto, aquella primera frase que daba comienzo a este primer capítulo: una deconstrucción de la pena de muerte no es solo una deconstrucción de la soberanía sino, ante todo, una deconstrucción del sistema teológico-político-jurídico sobre el que ésta se asienta. 
En el segundo de los capítulos nos encontramos con el autor en el que habíamos estado pensando constantemente a lo largo del apartado anterior: Carl Schmitt, con su célebre afirmación "soberano es quien decide sobre el estado de excepción". Ahora bien, desde Derrida, Delmiro Rocha subraya que el soberano no es sim-plemente quien decide qué se debe hacer en el estado de excepción, esto es, cómo se materializa el estado de excepción sino, primero y ante todo, cuándo nos encontramos ante una excepción. Sin embargo, si el soberano decide sobre el estado de excepción, es decir, si controla la excepción, y al mismo tiempo es quien establece la ley y la norma, el estado de excepción no viene a ser sino un estado normal del soberano, por lo que no habría excepción en absoluto: como afirma Delmiro Rocha, "el argumento de Schmitt normaliza la excepción. Convierte la excepción en norma" (p. 35). A esta excepción normalizada y contralada se contrapondría esa excepción inconmensurable que es el acontecimiento derridiano: lo que viene sin anticipación alguna, imprevistamente, fuera de control, más allá de todo programa y de todo cálculo. En definitiva, esto no es sino afirmar que solo la deconstrucción es capaz de pensar y dejar ser "propiamente" la excepción, el acontecimiento excepcional en la medida en que comprende que el acontecimiento no puede venir del "Otro mismo", del soberano que decide, sino del "cualquier otro", de todos los otros, incluso del otro "en mí", dejando vivir al otro, pues solo en el otro puede uno vivir.

La soberanía y la excepción nos conducen a analizar, ya en el tercer capítulo, la cuestión de la crueldad en la pena de muerte. De este modo, se comienza recordando ese momento histórico en el que la Corte Suprema de los Estados Unidos de América decretó en el año 1972 la ilegalidad de la pena de muerte al considerar que se trataba de un castigo cruel que vulneraba, por ello mismo, la octava enmienda. No obstante, como esta paralización basaba su justificación en el método de la pena de muerte, en su ejecución, en su forma, tan pronto como se encontró un método más humano de realizar la ejecución pudo volver a matarse a los condenados sin el peso y la culpa de la crueldad. Así, "tanto la lógica abolicionista como la lógica anti-abolicionista girarían en este sentido en torno al concepto de crueldad" (p. 46). De lo que se trataría, por tanto, desde la perspectiva abolicionista, no es tanto de demostrar que la forma en la que se ejecuta la pena de muerte es cruel, sino que la pena, en sí misma y por sí misma, es un hecho necesaria e inevitablemente cruel. Por ejemplo, mostrando que la crueldad no reside en los gritos y alaridos del reo, en la sangre y lo obsceno de la muerte, sino en el mero hecho de contar lo que no se puede contar, esto es, el tiempo del otro: la crueldad es poner fin a la indeterminación de la vida, matar la finitud de la vida. En este sentido, lo cruel de la pena de muerte no es quitar la vida, sino precisamente el dar aquello que no se debe dar, un saber, el saber del día de la muerte. Lo cruel en la pena de muerte, por tanto, no es su irracionalidad y su barbarismo, sino precisamente su ultrarracionalidad, su exceso de racionalidad o su racionalidad excesiva, el cálculo de lo no-calculable. La cuestión de la crueldad, por tanto, es en definitiva una cuestión económica, algo que Delmiro Rocha desarrolla en el cuarto capítulo.

La justicia económica más difundida, y cada vez con más seguidores, es sin duda la ley del talión. En este sentido, el "ojo por ojo, diente por diente" (del que Delmiro Rocha se encarga de recordarnos que tiene una continuación: "mano por mano, pie por pie, quemadura por quemadura, herida por herida, golpe por golpe"), es sin duda 
una transacción económica en la que un sujeto, el reo, salda una deuda contraída por medio de su delito. Esta economía ancestral, sin embargo, se funda en una transacción muy particular: en ella no hay interés, no hay plusvalía, no hay ganancia. El pago del deudor (la mano, el pie, la vida) es estrictamente equivalente a aquello que arrebató (una mano, un pie, una vida). Y en este sentido, más allá del hecho de que se puede argumentar tanto desde una posición anti-abolicionista con la Biblia en la mano, basándose en la ley del talión dada por Dios, como apoyándose de forma abolicionista en la buena nueva de su Hijo que nos enseña a poner la otra mejilla, la cuestión económico-teológica viene a señalar que solo Dios es capaz de sostener una economía circular, una economía sin plusvalía: dándose a sí mismo en sacrificio a través de Cristo, Dios Padre salda la deuda imposible de los hombres de su pecado, y por tanto señala que la ley del talión solo es posible en Dios y por Dios: desde que la justicia es humana, hay interés, hay beneficio, se esfuma la equivalencia. Ahora bien, ¿no es esto admitir que desde que hay interés en la justicia económica humana, ésta no puede ser desinteresada? Este "quien a hierro mata, a hierro muere" solo es aplicable, por tanto, en el reino de los cielos, mientras que aquí abajo no hay sino cálculo, precisamente de lo no-calculable, el tiempo del otro, y por tanto exceso, interés, desequilibrio, parcialidad. La pena de muerte no es solo cruel, como se indicó anteriormente, sino que es sencillamente falaz al considerar que los hombres pueden calcular, no lo incalculable, es decir, lo "demasiado grande" para ser calculado, sino lo heterogéneo al cálculo, lo no cuantitativo. Y esto que no se puede calcular, el tiempo del otro, si nos situamos en una deconstrucción de lo teológico-político, no puede ser contado ni por el soberano, ni por Dios, ni por la máquina de la colonia penitenciaria de Kafka.

El quinto capítulo se inicia como comienza el seminario en torno a la pena de muerte de Derrida: "¿qué responder a alguien que viniese a decirles, al alba: 'saben ustedes, la pena de muerte es lo propio del hombre'?". En este sentido, a la deconstrucción de la soberanía, que no es sino una deconstrucción del cristianismo, Delmiro Rocha viene a añadir la necesaria "deconstrucción del hombre" (p. 89). Así, toma como punto de partida la posición de Victor Hugo, para quien matar a una mujer mediante la pena de muerte resultaría un hecho penoso. De este modo, Hugo no estaría tratando de la mujer concreta, de esta mujer ("una mujer llamada... - ¿qué importa el nombre?"), sino de la figura de la mujer, de la mujer como figura. Con vistas a combatir una violencia que considera deplorable, la pena de muerte, Victor Hugo materializa una segunda violencia, una violencia sin sangre, sin escarnio público: la exclusión de la mujer. En este sentido, desde una perspectiva kantiana, es decir, aceptando que la dignidad del hombre se encuentra siempre "por encima" de los hombres particulares y, por tanto, es justo ejecutar a este hombre en favor del todos, porque el hecho de poder ser ejecutado legalmente se basa en que el reo es humano y es hombre, es decir, es digno, lo que vendría a señalar Victor Hugo, como afirma Delmiro Rocha, es que "lo propio de la mujer sería no pertenecer a lo propio del hombre" (p. 106). De este modo, para luchar contra la pena de muerte sin caer en otra forma de violencia, en la violencia de la exclusión, resulta imprescindible reconfigurar ese mundo propio del hombre, de los hombres: la deconstrucción de la pena de muerte es, por tanto, una deconstrucción de Dios, pero también una deconstrucción del hombre. 
El último capítulo comienza también con una interrogación: “¿se puede condenar a muerte a un animal?" (p. 109). En este sentido, Delmiro Rocha destaca en primer lugar que, tal y como sucede con el "una mujer", el hecho de hablar de "un" animal, de "los" animales, elimina toda diferencia y toda heterogeneidad en el animal, manteniendo, sin embargo, una última frontera: Animal / Hombre. Así, si la pena de muerte se aplica a "un" animal, ¿se estaría aplicando a una generalidad, es decir, a todos los animales? ¿Estarían, por tanto, todos los animales condenados a muerte? ¿Se trataría, entonces, de un genocidio? Intentando resolver estas cuestiones nos topamos, de nuevo, con que no resultan sino una cuestión teológica: es la Biblia quien determina que lo propio de un animal, de un animal muerto, es servir de alimento al hombre y, por tanto, "el animal es un ser condenado a muerte desde el momento en que su existencia se define como alimento" (p. 117). Si la deconstrucción de la pena de muerte nos hace movernos continuamente en el terreno de la teología política, en este caso de la teo-alimentación, podría afirmarse que el vegetarianismo constituiría una suerte de "desobediencia teológico-política" (p. 119), esto es, una teoría de la justicia. Sin embargo, la verdadera cuestión a tratar en esta dietética teológica, más allá de la "cuestión animal", no es sino la de la aporética relación con el otro en cuanto apropiación de la alteridad, lo que conduce a "la imposibilidad de la abolición de la pena de muerte" (p. 124), o lo que es lo mismo, la posibilidad imposible de su abolición.

Seis cuestiones, por tanto, que no hacen sino revelar la pertinencia de plantear la pregunta por la pena de muerte, la cuestión de la imposibilidad de que la pena de muerte sea imposible. Seis cuestiones que hacen de este libro no un comentario, ni un ensayo, ni un opúsculo, sino una verdadera deconstrucción de la teología política, una deconstrucción del cristianismo. Una invitación, por tanto, a pensar las cuestiones de nuestro presente tomando como punto de partida la obra de Derrida, es decir, haciéndonos herederos de su obra, inventores de sus cuestiones, aquí y ahora.

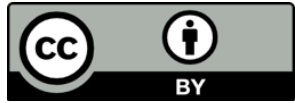

